\title{
HALOTHANE (FLUOTHANE) ANAESTHESIA FOR PAEDIATRIC CARDIAC SURGERY
}

\author{
Cyril Taylor, m.D., and V. K. Stoelting, M.D.**
}

HALOTHANE, 1,1,1,-trifluoro-2,2, bromochloroethane, is a volatile halogenated hydrocarbon, which was introduced in 1956 as a general anaesthetic agent.1, 2, 3 It appeared during an era of enlightenment in anaesthesiology, and more zeal has been directed to the investigation and clinical application of halothane than immediately followed the introduction of any other anaesthetic agent. In the past few years, halothane has established itself as a valuable addition to the armamentarium of anaesthetic drugs.

There has been an increasing tendency in recent years to utilize electric devices during cardiac surgery. The surgeon may require electrocautery or the electric saw; the pumps are electrically operated, and the anaesthesiologist has adapted electronic instruments to aid him in the care of the patient during the operation. Frequently, therefore, a non-explosive anaesthetic technique is mandatory. Prior to the introduction of halothane, there was no non-inflammable inhalation anaesthetic which was suitable for administration to patients during heart surgery. Halothane, however, possessed certain features which merited consideration. Since early studies of halothane emphasized the myocardial depressant properties of the new drug, ${ }^{1,4}$ there was an initial reluctance to administer halothane to patients with myocardial disease.

When halothane was first employed at Indiana University Medical Center, it was observed that patients with acquired and congenital heart disease tolerated the agent very well, if light levels of anaesthesia were maintained. There appeared to be a clearly defined need, at that time, for a noh-inflammable inhalation anaesthetic which could be used during cardiac surgery. It was decided, therefore, to evaluate halothane anaesthesia in this role. The early results were encouraging and the study was continued.

The following report describes the clinical experiences with the administration of halothane anesthesia to 200 children during the surgical correction of congenital cardiac effects.

\section{Clinical Material}

The data which is reported has been obtained from medical records at Indiana University Medical Center. All of these patients were less than 16 years of age (Fig. 1). A variety of cardiac lesions and operations were encountered during this series (Table I). Extracorporeal circulation and moderate hypothermia were

*Indiana University Medical Center, Indianapolis, Indiana.

Can. Anaes. Soc. J., vol. 8, no. 3, May, 1961. 


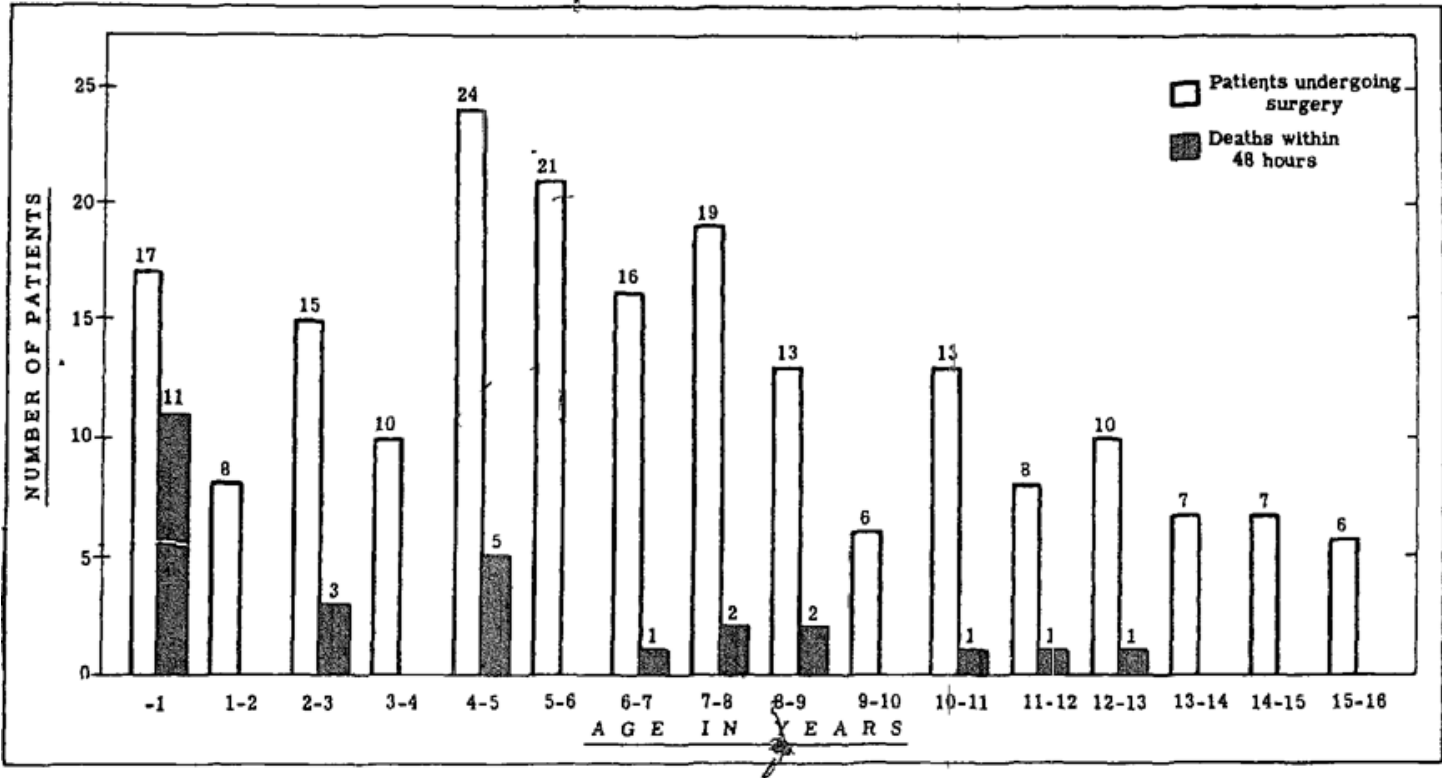

FIGURE 1. The age distribution of the 200 children, and of those childran who died within 48 hours.

used during 108 of these operations to allow the defects to be repaired under direct vision, but were not required in the remaining operations.

\section{ClinínicAL Method}

The children received $0.1 \mathrm{mg}$. of morphine sulfate or $1.0 \mathrm{mg}$. of meperidine hydrochloride (Demerol ${ }^{\circledR}$ ) per pound of body weight, by intramuscular injection, one and one-half hours before surgery. Ten $\mathrm{mg}$. of morphine or $100 \mathrm{mg}$. of meperidine were the maximal amounts administered to any patient.

The first seventy of these patients who underwent open heart surgery received neither atropine sulfate nor scopolamine hydrobromide. The anticholinergic drugs were omitted at the behest of the surgeon since it was feared that they might antagonize the effect of acetylcholine, which was employed when necessary to produce elective cardiac arrest during the cardiotomy. Atropine was injected intravenously during the course of some of these operations, and later, preoperatively, by intramuscular injection. Elective cardiac arrest could still be produced in these patients by the injection of acetylcholine. The remaining patiénts received atropine or scopolamine by intramuscular injection, in doses appropriate for their age and weight, when the narcotic was injected.

In the early part of this study, anaesthesia was induced by the inhalation of 50 per cent nitrous oxide in oxygen, to which halothane was added gradually from an accurately calibrated vaporizer. This technique allowed a rapid and quiet induction of anaesthesia, and the endotracheal intubation. Two serious difficulties were encountered. High concentrations of halothane, up to 2.4 per cent, were used to achieve these results, and some of the children developed alarming hypotension and bradycardia in response to these concentrations. It was possible, fortunately, to resuscitate all of these children. The other difficulty arose 
TABLE I

The Distribution of the 200 Children, and Those Children Who Died withrn 48 Hours, in Relation to the Type of Cardiac Defect

\begin{tabular}{|c|c|c|}
\hline & $\begin{array}{l}\text { Number of } \\
\text { patients }\end{array}$ & $\begin{array}{l}\text { Number of deaths } \\
\text { within } 48 \text { hours }\end{array}$ \\
\hline \multicolumn{3}{|l|}{ Intracardiace (open heart) surgery } \\
\hline Atrial septal defect & 33 & 1 \\
\hline Ventricular septal defect & 23 & 4 \\
\hline Tetralogy of fallot & 18 & 7 \\
\hline Pulmonary stenosis & 13 & 2 \\
\hline \multicolumn{3}{|l|}{ Anomalous pulmonary } \\
\hline $\begin{array}{l}\text { venous return } \\
\text { Miscellaneous }\end{array}$ & $\begin{array}{r}8 \\
13\end{array}$ & $\begin{array}{l}2 \\
2\end{array}$ \\
\hline TOTAL & 108 & 18 \\
\hline \multicolumn{3}{|l|}{ Extracardiac surgery } \\
\hline \multicolumn{3}{|l|}{ Transection of patent } \\
\hline ductus arteriosus & 36 & 0 \\
\hline Blalock or potts procedure & 24 & 1 \\
\hline Pulmonary artery banding & 12 & 6 \\
\hline Pulmonary valvulotomy & 10 & 0 \\
\hline Resection of coarctation of the aorta & 8 & 0 \\
\hline Creation of interatrial septal defect & 2 & 2 \\
\hline TOTAL & 92 & 9 \\
\hline
\end{tabular}

when there was some delay in the introduction of the endotracheal tube into the trachea. Laryngospasm or severe coughing occurred, and the accompanying hypoxia was a most disturbing and undesirable feature. The use of this technique, therefore, to induce anaesthesia in these patients was abandoned.

Following this decision, anaesthesia was induced, when the child permitted venepuncture, by the slow intravenous injection of a 1.0 per cent solution of methohexital sodium (Brevital $\left.{ }^{\oplus}\right) .{ }^{5}$ Oxygen was then administered by intermittent positive pressure, and succinylcholine solution was injected 'intravenously to provide muscular relaxation, so that an endotracheal tube could be inserted into the trachea. With the other children, the induction of anaesthesia was accomplished by the administration of divinyl ether (Vinethene) and diethyl ether by the open drop method, and endotracheal intubation was performed when the muscular relaxation appeared adequate.

During the operation, a steady level of anaesthesia was maintained by the administration of a mixture of 50 per cent nitrous oxide in oxygen, to which halothane was added in concentrations up to 0.8 per cent. Adjustments were made within this range to provide immobility of the patient. Electroencephalograms demonstrated patterns 1 or 2 when these concentrations of halothane were employed. ${ }^{6}$ The halothane was administered in oxygen, instead of nitrous oxide and oxygen, when warranted by the patient ${ }^{2}$ condition. A flow rate of eight litres of anaesthetic mixture per minute and a semi-closed to and fro absorption system allowed the elimination of endogenous carbon dioxide. Respiration was controlled throughout the operation. Apnoea was produced quite readily, in most of the patients, by hyperventilating them with the anaesthetic 
mixture. Succinylcholine was administered, when indicated, to reinforce the effect of the hyperventilation, and to ensure the avoidance of coughing at critical points in the surgical procedure. The succinylcholine was injected as a 0.2 per cent solution by continuous intravenous drip infusion with children over two years of age. With the younger children the muscle relaxant was injected intermittently, in doses of 1.0-1.5 mg. per pound of body weight by the intramuscular or intravenous routes to avoid the danger of infusing excessive amounts of fluid.

Halothane was not administered to the patients during the cardiopulmonary by-pass in open heart operations. Previous experience had shown that the dangerous cardiac arrhythmias occurred almost exclusively during or following the cardiotomy. When halothane was first introduced it had the reputation of enhancing myocardial irritability. ${ }^{7}$ It appeared advisable, therefore, to refrain from exhibiting halothane during this stage of the operation. Instead, methohexital sodium (Brevital ${ }^{\circledR}$ ) was introduced into the oxygenator chamber to provide sedation, and succinylcholine solution was injected into a peripheral vein to ensure complete immobility of the diaphragm.

Controlled respiration was maintained until surgery had been completed, when oxygen was administered through the endotracheal tube and a complete tracheobronchial toilet was performed. The endotracheal tube was removed when the child appeared to be awakening, and the administration of oxygen was continued with a face mask. When spontaneous ventilation appeared to be adequate, the patient was taken to the recovery room.

\section{RESULTS}

The number of deaths which occurred during surgery or during the tirst 48-hour postoperative period are shown in relation to the cardiac defect (Table I) and to the age of the patient (Fig. 1). It was the combined opinion of the anaesthesia and surgical teams that the anaesthetic agents were not responsible for any of these deaths. Mortality figures in cardiac surgery are misleading unless special regard is paid to the physical condition of the child and to the nature of the surgery. The table includes children with such severe cardiac disease that death was inevitable in the immediate future, and surgery was offered in desperation as the only hope for amelioration. It was the rare success which justified the acceptance of these moribund patients. If the operation failed to improve their condition appreciably, they succumbed to the stress of the operation during or immediately following the procedure.

Anaesthesia was induced in fifteen children by the inhalation of a halothane, nitrous oxide, and oxygen mixture. Nine of these children developed severe hypotension and bradycardia. An emergency thoracotomy was necessary in only one patient, and the heart was still beating when it was exposed. All of these patients responded to the elimination of the halothane, to ventilation with oxygen, and to the intravenous injection of atropine sulfate. The operation was abandoned in the case of the child who had the thoracotomy, but was continued with the other children using light halothane anaesthesia. No further difficulties were encountered during these operations which çould be attributed to the use of halothane. 
The systolic blood pressure was depressed $10-20 \mathrm{~mm}$. $\mathrm{Hg}$ and the pulse rate 20-30 beats per min. from the pre-anaesthetic resting level in most of these children. With patients who were undergoing open heart surgery, it was found that if some degree of hypotension was present the intramuscular injection of metaraminol (Aramine ${ }^{\circledR}$ ) prior to the cardiopulmonary by-pass allowed a higher pressure to be maintained during the perfusion. Severe hypotension did occur during some of these cases, but was associalted with rapid blood loss, surgical manipulations within the thorax, and the terminal deterioration of the moribund patients.

Manipulation of the heart to allow the corrective surgical procedure is almost invariably accompanied by the appearance of various types of cardiac arrhythmias, whichever anaesthetic agent has been selected. There were other arrhythmias which developed during anaesthesia. Ventricular extrasystoles occurred with 25 patients, auricular extrasystoles with 15 patients, and nodal rhythm with eight patients. These were transitory and appeared to be associated with inadequate ventilation or surgical manipulations. Two patients demonstrated nodal tachycardia and one patient ventricular tachycardia during open heart surgery. They resumed a sinus rhythm within 24 hours.

Ventricular fibrillation was observed with 11 patients. This occurred during the cardiopulmonary by-pass in 10 children, who were undergoing open heart surgery. Acetylcholine had been injected to produce elective cardiac arrest in eight of these patients. This complication has been noted following the use of acetylcholine and potassium citrate for this purpose. ${ }^{8}$ It was difficult to implicate halothane in any of these cases, since none had been administered during the by-pass. Any residuum from the freceding stage of the operation can be assumed to have been eliminated in the oxygenator chamber. It was possible to revert the ventricular fibrillation to a sinus rhythm in nine of these patients.

Cardiac asystole occurred during operations on six children. All of these children were moribund before anaesthesia was commenced. There was no reason to believe that they would have survived if some other anaesthetic technique had been selected.

Samples of arterial blood were obtained from 23 children during cardiac surgery (Fig. 2). The first sample was obtained when the patient was breathing spontaneously following the endotracheal intubation, and the effects of the drugs which had been employed to induce anaesthesia had abated. Mild respiratory depression was evident. The second and third were removed during the operation and demonstrated that adequate arterial carbon dioxide tensions could be maintained with adequate ventilation of the patient. The final sample was obtained just before the child was removed from the operating room. The patients were awake and were breathing spontaneously. The near normal tensions of carbon dioxide in the arterial blood confirmed the fact that adequate ventilation returned rapidly following anaesthesia with low concentrations of halothane.

\section{Discussion}

The skill and experience of the anaesthesiologist are the most important factors in the successful conduct of anaesthesia during cardiac surgery. The significance 


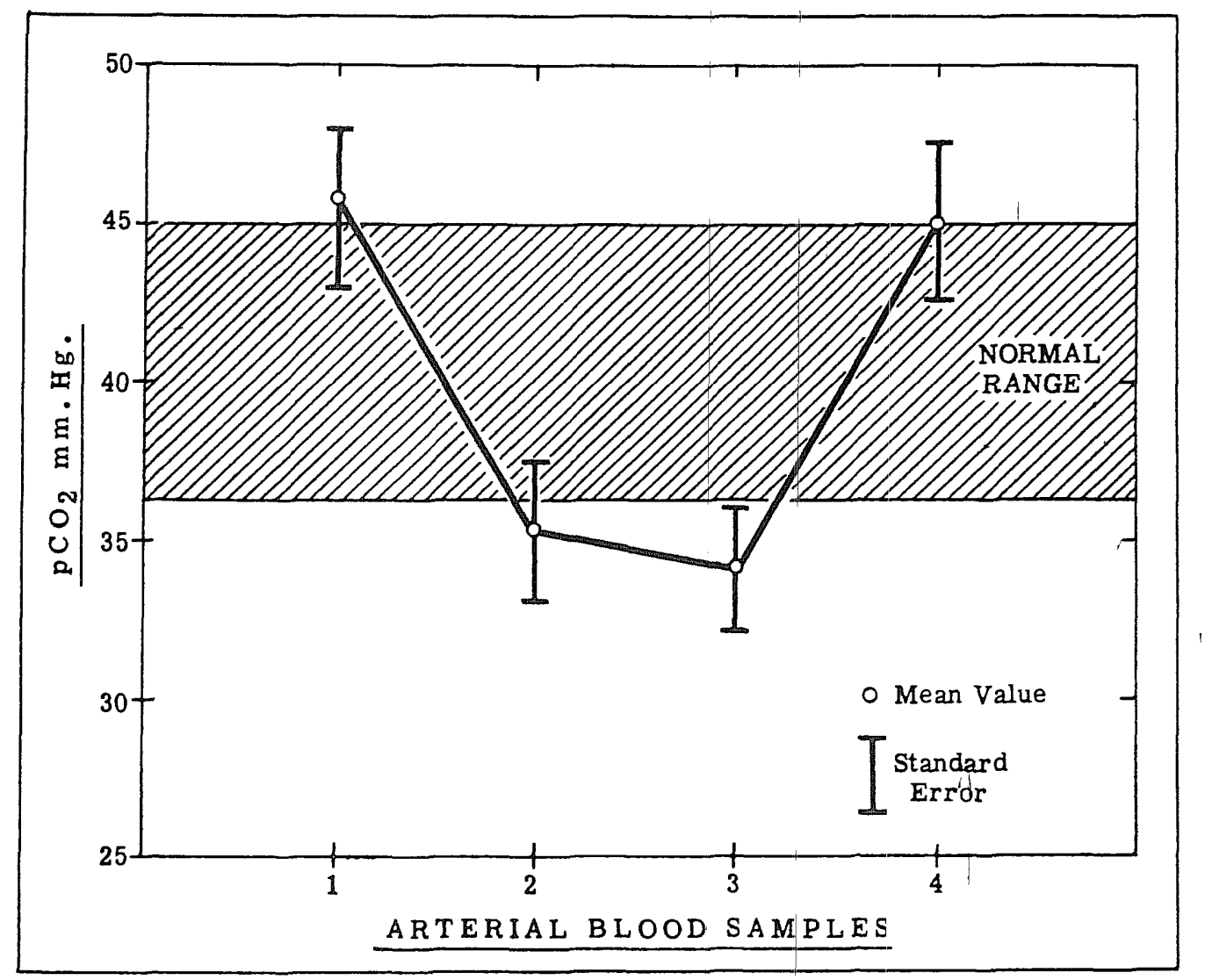

FIGURE 2. A graphic representation of the tensions of carbon dioxide in the arterial blood of 23 children, during and immediately following surgery, in relation to the normal range. ${ }^{14}$

of the selection of anaesthetic agents, however, should not be belittled. Although most of the popular anaesthetic agents have been used successfully to anaesthetize these patients, there appeared to be a need for a satisfactory non-inflammable inhalation anaesthetic so that electric instruments could be used safely during the operation. Halothane satisfied this requirement, and this study has shown that it was eminently suitable to provide anaesthesia during cardiac surgery, when administered in low concentrations.

Light halothane anaesthesia provided amnesia, analgesia, and immobilitythe basic requirements of general anaesthesia during this type of surgery. A steady and predictable level of anaesthesia was maintained throughout the operation with delightful simplicity by the adjustment of a calibrated vaporizer. The absence of significant respiratory depression in the immediate postoperative period was demonstrated by the measurement of the tension of carbon dioxide in arterial blood. Halothane, when used in low concentrations, was rapidly eliminated following the termination of anaesthesia. This allowed a rapid awakening of the patient and a rapid return of adequate ventilatory exchange. Apnoea was obtained readily in most of these children when they were hyperventilated with the anaesthetic mixture. Muscle relaxants, therefore, were employed merely to reinforce this effect, thus reducing the amount of the relaxant which was 
required during the operation. This factor also favoured the rapid return of adequate ventilation following the termination of anaesthesia.

The ability to administer anaesthetic mixtures containing high concentrations of oxygen is essential when anaesthetizing patients with cardiac disease. Any desired concentration of oxygen could be offered to these patients without any appreciable alteration in the concentration of halothane.

The most strenuous arguments against the employment of halothane when the patient has cardiac disease have been based on the alleged myocardial depressant effect of the drug. Investigations in humans and animals, however, have clearly demonstrated that there is no appreciable cardiovascular depression during light halothane anaesthesia. ${ }^{9}$ Measurement of the cardiac output and the ventricular contractile force have revealed no significant decrease in these parameters when low concentrations were used.10.11 In this clinical study, light halothane anaesthesia provided adequate anaesthesia to patients with heart disease throughout the operation. When the concentrations were maintained at 0.8 per cent or less, no cardiovascular depression of any consequence occurred which could be attributed to the action of halothane.

There appears to be little doubt that, in common with other anaesthetic agents, deep halothane anaesthesia caúses depression of cardiac function. Severinghaus and Cullen found a decrease in the cardiac output and the stroke volume of human volunteers who were artificially ventilated with 1.5 per cent halothane. ${ }^{4}$ They concluded that this was the result of myocardial depression. McGregor and his colleagues ${ }^{10}$ showed that the cardiac output was decreased in normal children during moderate or dop anaesthesia. They were reluctant to ascribe this entirely to myocardial depression. Sprouse, Thrower, and their group ${ }^{11,12}$ measured the ventricular contractile force and the cardiac output in humans and animals during deep halothane anaesthesia, and found a decrease of 40-50 per cent in each from the control values. They noted a return in the cardiac output to near control values when atropine was injected, and concluded that the decrease was associated with the bradycardia, rather than with myocardial depression. Cardiac depression was observed in the patients with cardiac disease, included in this series, when anaesthesia was induced with high concentrations of halothane. Alarming hypotension and bradycardia appeared abruptly, and there was little doubt amongst those present that cardiac arrest would have been the obvious sequel if resuscitation had not been carried out promptly. A thoracotomy was performed on one of these children who had received 2.4 per cent halothane, and although the heart was still beating and appeared well-oxygenated, there could be little question that there was dangerous depression of cardiac function. It is true that not all of the children in whom anaesthesia was induced with high concentrations of halothane demonstrated this severe depression, but the frequency of this dangerous complication was sufficient to condemn this technique.

There are no non-inflammable inhalation anaesthetic agents except halothane and nitrous oxide which are suitable for anaesthetizing patients during cardiac surgery. Other non-explosive anaesthetic techniques depend on the supplementation of nitrous oxide and oxygen anaesthesia by the intravenous injection of 
bartiturates and narcotics. Inhalation anaesthetics can be eliminated readily through the respiratory tract by ventilating the patient. Drugs which have been injected intravenously must await complex pharmacophysiologic processes, which may be retarded when the patient has been subjected to the rigours of cardiac surgery. The facility with which inhalation agents can be removed from the patient allows more rapid correction of the effects of an overdose, greater ease in maintaining a steady level of anaesthesia, and a greater assurance that hypnosis and respiratory depression will be minimal when anaesthesia has been terminated.

Halothane anaesthesia has been used exclusively at this institution during the past three years with patients undergoing open heart surgery. Any comparison of these patients with those who underwent intracardiac surgery prior to the use of halothane is not valid. The decrease in the frequency of anaesthetic and surgical complications, and in the mortality rate, is due primarily to the increase in the skill of the surgical and anaesthesia teams. There are certain heart operations, however, which have become standardized with regard to surgical technique and anticipated complications, so that a comparison of the effects of the different anaesthetic agents employed appears to be reasonable. Two groups of 68 children were compared. The first group received halothane anaesthesia, and the second cyclopropane or ether anaesthesia. They underwent surgery to correct either a patent ductus arteriosus, a coarctation of the aorta, or, by extracardiac anastomosis, a tetralogy of Fallot. One patient in each group died during the postoperative period. Cardiovascular depression and cardiac arrhythmias occurred with nearly equal frequency in both groups. These appeared to be due to surgical manipulations or errors in anaesthetic technique, and not to the anaesthetic agents. The arterial blood pressure was usually maintained at a higher level during cyclopropane anaesthesia, and the pulse rate stabilized at a lower rate during cyclopropane and halothane anaesthesia. No patients in either group manifested severe hypertension during the postoperative period following the surgical repair of coarctation of the aorta. ${ }^{13}$ There did not appear to be any significant difference in the response of the patient during anaesthesia, whichever anaesthetic agent was employed.

\section{Summary and Conclusion}

Light halothane anaesthesia was administered to 200 children during cardiac surgery. The principle advantages of halothane, when compared to other inhalation annaesthetics, was its lack of flammability. The children tolerated the agent very well if low concentrations were employed, but frequently developed alarming signs of cardiac depression with high concentrations of halothane.

Halothane could not be recommended to induce anaesthesia for cardiac surgery. It was safe, and provided satisfactory anaesthesia, when light halothane anaesthesia was maintained throughout the operation. Light halothane anaesthesia merits serious consideration when a non-inflammable anaesthetic technique is required during cardiac surgery. 


\section{RÉSUMÉ}

L'apparition, au cours des dernières années, d'appareils électriques comme adjuvants au cours de la chirurgie cardiaque, nous a placés dans l'obligation d'employer au cours de cette chirurgie un agent anesthésique non explosif. Quand l'halothane est apparu comme agent anesthésique, on a insisté sur son effet dépresseur sur le myocarde. Toutefois, l'expérience révèle que, si l'on emploie de faibles concentrations, même les porteurs de maladies cardiovasculaires le tolèrent très bien.

$\mathrm{Au}$ cours de ce travail nous décrivons, chez 200 enfants ayant subi de la chirurgie cardiaque, comment nous avons administré l'halothane avec le protoxyde et l'oxygène. Nous avons observé que, sinous employions de fortes concentrations d'halothane, les enfants prêsentaient souvent des dépressions cardiovasculaires inquiétantes. Pour l'induction, nous avons donc employé d'autres agents anesthésiques. Pour le maintien de l'anesthésie, l'halothane, administré à une concentration ne dépassant pas $0.8 \%$ avec du protoxyde et de l'oxygène, a produit un niveau d'anesthésie tout-à-fait convenable.

Nous ne pouvons pas attribure à l'halothane aucune des morts survenues au cours de la chirirgie et au cours des quarante-huit heures qui l'ont suivie. Nous n'avons recontré aucune difficulté importante aussi longtemps que nous n'avons pas dépassé une concentration de $0.8 \%$. La recherche de la tension du gaz carbonique dans le sang artériel nous a démontré que toute dépression respiratoire attribuable à l'halothane disparaissait rapidement à la fin de l'anesthésie.

Nous pouvons conseiller l'usage de l'halothane'au cours de la chirurgie cardiaque lorsqu'il s'impose d'employer un agent non explosif.

\section{REFERENCES}

1. Raventos, J. The Action of Fluothane-A New Voltaile Anaesthetic, Brit. J. Pharmacol. 11: 394 (1956).

2. Bryce-Smith, R., \& O'Brien, H. D. Fluothane, A Non-Explosive Volatile Anaesthetic. Brit. Med. J. ii: 969 (1956).

3. Brennan, H. J., Hunter, A. R., \& Johnstone, M. Halothane: A Clinical Assessment. Lancet $i i: 453$ (1957).

4. Severinghaus, J. W., \& Cullen, S. C. Depression of Myocardium and Body Oxygen Consumption. Anesthesiology 19: 165 (1958).

5. Taylor, C., \& Stoelting, V. K. Methohexital Sodium-A New Ultra-short Acting Barbiturate. Anesthesiology 21: 29 (1960).

6. Given, J. B., Little, D. M., \& Tovell, R. M. Heart Sounds During Fluothane Anesthesia, Canad. Anaesth. Soc. J. 4: 282 (1957).

7. Burnap, R. T., Galla, S. J., \& Vandam, L. D. Anesthetic, Circulatory and Respiratory Effects of Fluothane. Anesthesiology 19: 307 (1958).

8. Mendlesohit, D., Jr.; MacDonald, D. W.; Nogueria, C.; \& Kay, E. B. Anesthesia for Open Heart Surgery: Acquired Valvular Disease. Analg. and Anes. 39: 110 (1960).

9. Doвkin, A. B. Circulatory Dynamics During Light Halothane Anesthesia. Brit. J. Anaesth. 30: 568 (1958).

10. McGregor, M.; Davenport, H. T.; Jegier, W.; Serely, P.; Gibbons, J. E.; \& Demers, P. P. The Cardiovascular Effects of Halothane in Normal Children. Brit. J. Anaesth. 80 : 398 (1958). 
11. Sprouse, J. H.; Mahaffey, J. E.; Darby, T. D.; \& Hall, J. A. A Comparison of the Effects of Fluothane and Ether on the Ventricular Contractile Force of the Human and Dog. Anesthesiology 22: 145 (1961).

12. Thrówer, W. B.; Darby, T. D.; Aldinger, E. E.; \& Sprouse, J. H Effects of Halothane (Fluothane) Anesthesia on the Ventricular Contractile Force in the Human and Dog. Fed. Proceedings 19: 274 (1960).

13. Davis, T. B.; Morrow, D. H.; Cooper, T.; \& Hebert, C. L. Paradoxical Hypertension Following Resection of Aortic Coarctation Under Halothane Anesthesia. Anesthesiology 22: 132 (1961).

14. National Research Council: Handbook of Respiration. Philadelphia, Pa.: W. B. Saunders (1958). 